\title{
Smoother than smooth: increasing the flow conveyance of an open-channel flow by using drag reduction methods
}

Emmanuel Mignot ${ }^{1}$, Nicolas Riviere $^{2}$, Arnaud Lefevre ${ }^{3}$, Bernard Quillien ${ }^{4}$

${ }^{1}$ Ass. Prof., Univ Lyon, INSA Lyon, CNRS, LMFA UMR5509, 20 av. A Eintein, F-69621 Villeurbanne, France.Emmanuel.mignot@insa-lyon.fr

${ }^{2}$ Prof., Univ Lyon, INSA Lyon, CNRS, LMFA UMR5509, 20 av. A Eintein, F-69621 Villeurbanne, France.Nicolas.riviere@insa-lyon.fr

${ }^{3}$ Sales Director, SNF SAS, Rue Adrienne Bolland, ZAC de Milieux, 42163 Andrézieux Cédex, France. alefevre@snf.fr

${ }^{4}$ Tech., SNF SAS, Rue Adrienne Bolland, ZAC de Milieux, 42163 Andrézieux Cédex, France. bquillien@snf.fr

\section{$\underline{\text { Abstract }}$}

The drag reduction method by polymer additives is a common strategy used to minimize friction losses when carrying fluids (water, oil, slurries) in pipes over long distances. Previous studies showed that the interactions between the polymer and the turbulent structures of the flow tend to modify the streamwise velocity profile close to the walls by adding a so-called elastic sublayer between the classical viscous and log layers. The gain in linear head losses can reach up to $80 \%$, depending on the roughness of the walls and the concentration of polymers. The application of this technique to sewers and the subsequent gain in discharge capacity motivated this work to quantitatively measure the drag reduction in classical open-channel flows. Three measurement campaigns were performed in a dedicated long flume for several water discharges and several polymer concentrations: backwater curves over smooth and rough channel walls (including velocity and turbulent shear stress profiles) and flows around emerging obstacles. The addition of polymers, even in limited concentrations, allowed a high friction decrease with a typical Darcy-Weisbach coefficient reduced by factors of 2 and 1.5 , respectively in smooth and rough walls configurations without obstacles; but without strong modifications of the non-dimensional velocity profiles. Oppositely, when adding emerging obstacles, 
the flow was unaffected by the inclusion of polymers, in agreement with the prediction of the literature. The drag-reduction method by addition of small concentrations of polymers finally appears to be a promising technics to increase the flow conveyance in open-channel flows.

\section{$\underline{\text { Introduction }}$}

Discovered by Toms in 1948 (see Toms, 1949), the drag reduction effect by polymer addition is a common strategy used to minimize friction losses when carrying fluids over long distances. This effect is commonly used "in oil pipeline conduits, oil well operations, flood water disposal, firefighting, field irrigation, transport of suspensions and slurries, sewer systems, water heating and cooling systems, airplane tank filling, marine systems, and biomedical systems including blood flow" (Brostow, 2008). Han et al (2017) recently reviewed all available water-soluble macromolecules that permit to reduce the drag of turbulent flows, "including both natural and synthetic polymers". While drag reduction can also be obtained by inserting other additives in water, such as fibers or surfactants, this paper only deals with polymeric additives. Moreover, the present work is limited to solutions with very low polymer concentrations (a few tens of parts per million ppm).

The drag reduction effect allows to dramatically reduce the wall friction and thus the linear head losses by up to $80 \%$ (Herzhaft, 2000; White et al., 2018). The origin of this phenomenon lies in the interactions between the turbulent structures of the flow and the polymer macromolecules added to the fluid (Schlichting, 1979). In a fully-developed flow over a smooth bed, the polymers modify the velocity profile in the boundary layer. With clear-water, the velocity profile in the near-wall regions is composed of the laminar viscous sub-layer very close to the wall $(y u * / v<10$ with $y$ the distance to the wall, $u^{*}$ the friction velocity and $v$ the kinematic viscosity of the liquid) and the log law slightly further away $(y \mathrm{u} * / v>50)$. When adding polymers, a so-called "elastic zone" can be observed in between these two zones, for $y^{+}>15$ (Virk, 1975, Cai et al., 2009), within which the velocity profile follows a logarithmic law with a slope that depends on the polymer concentration. It is reported that as the extension of this zone increases, the drag reduction efficiency also increases. If this elastic zone occupies the whole flow section, the maximum drag reduction asymptote (MDRA) is reached and 
increasing the polymers concentration will not permit to further reduce the friction coefficient. However, White et al. (2018) recently suggested that when approaching the MDRA, the velocity profile tends to depart from a logarithmic law. They also observed that as the drag reduction increases, the extension (away from the wall) of the viscous sublayer increases and in return, the logarithmic or quasi-logarithmic layers are moved further away from the wall. Moreover, Virk (1975) shows that drag reduction can only be observed for a minimum wall shear stress magnitude.

Virk (1971) also investigated the possibility of polymers to reduce the drag over rough surfaces. He observed that for walls with large enough roughness elements, the wall roughness tends to decrease the drag reduction process. The author could establish useful asymptotic regimes of drag reduction as a function of the relative roughness, flow and polymeric parameters. These regimes are based on the common non-dimensional roughness height parameter $k_{s}{ }^{+}$defined as $k_{s}{ }^{+}=k_{s} \mathrm{u} * / v$, with $k_{s}$ the equivalent sand roughness height. His main conclusions are that, for a water-polymer mixture, the effect of wall roughness begins to be effective for $k_{s}^{+}>12$ (compared to $k_{s}^{+}>5$ in pure water). This confirms that the extension of the viscous sublayer increases when adding polymers. Then for $12<k_{s}{ }^{+}<50$, an "effectively smooth regime" is observed, and for ${k_{s}}^{+}>50$ the drag reduction decreases compared to the smooth regime up to the experimental limit of $k_{s}{ }^{+} \sim 150$.

On a local scale, the interactions between the polymer and the turbulent structures (of different scales) remain poorly understood and research on this topic is still going on (Herzhaft, 2000). Achia and Thompson (1977) and Tiederman et al. (1985) showed that the polymers tend to decrease the frequency of occurrence of the so-called turbulent ejections ( $w^{\prime}>0$ et $u^{\prime}<0$ with $w$ the wall normal and $u$ the streamwise velocity components and where the prime denotes time-fluctuations) and to increase their transverse spacing. The streamwise turbulent Reynolds stress increases while the wall-normal component decreases (see Harder and Tiederman, 1991). Moreover, the Reynolds shear stress in the elastic zone decreases due to the polymer insertion so that the total stress also decreases. A hypothesis is that aggregates of polymers of size comparable to the smaller turbulent scales can limit the existence of these small scale turbulent structures and thus limit the global turbulent intensity. Min et al (2003) proposed the following mechanism: the polymers in the very near-wall region store elastic energy 
taken from the flow and release it further from the wall as they are transported to the buffer layer by coherent turbulent structures.

Most works, cited above, report the use of drag reduction polymers in pressurized pipe or channel flows. However, a few tests have also been performed in open-channel flows, especially within sewer systems (see Sellin 1988). Hart et al (2011) reported the use of such polymers in the sewer network of the city of Whistler (Canada) during the 2010 Winter Olympic games where the waste water discharge was strongly increased due to a particularly high population in the area. Their figures 6-7, for instance, show a strong water depth decrease and velocity increase in a given open-channel pipe flow during a "high flow polymer dosing trial": in about one hour, the typical water depth decreases from about 15 to $2 \mathrm{~cm}$ while the typical velocity increases from 2.2 to $3.4 \mathrm{~m} / \mathrm{s}$. Use of polymers in urban flows is made possible by the Materials Safety Data Sheet (MSDS) information for anionic polymers that indicates that the chemicals are non-toxic at limited dose concentrations (Hart et al. 2011). Apart from these engineering applications in sewer networks, very little attention seems to have been devoted to drag reduction in open-channel flows. Janosi et al. (2004) investigated the effect of adding polymers to a dam break flow experiment on both initially dry and wet beds. Their results confirm Cadot et al (1998) observations that drag reduction is only effective if "turbulence is forced by a smooth boundary layer and the phenomenon vanishes in inertially forced turbulent flows".

To conclude, even though drag reduction is commonly used in pressurized flows, no academic work could be encountered on the analysis of drag reduction additives in open-channel flows (representatives of river or sewer flows). The aim of the present work is thus to fill this gap and estimate the drag reduction efficiency in open-channel flows over smooth and rough beds, with and without obstacles. The dedicated experimental open-channel flume and measurement techniques are introduced in section 1 along with a description of the tested polymer additives. Then, the flow characteristics (water depths and velocity profiles) are measured with and without polymers and compared to each other i) under smooth bed conditions in section 2, ii) under rough bed conditions in section 3, and iii) under smooth bed conditions but with a series of emerging obstacles in section 4 . 
Polymers are tested herein in open-channel configurations using natural ground water at temperatures between $10^{\circ} \mathrm{C}$ and $20^{\circ} \mathrm{C}$, with and without polymers. The additives are water-soluble polyacrylamide polymers (PAM or PAAM), commonly used as flocculants in water treatment processes (drinking water and waste water), as described by Han et al. (2017). Fig. 1 shows the results of rheological tests performed with the natural water without and with polymers collected at the inlet and outlet of the flume. It reveals that the water/polymers mixture remains Newtonian and its viscosity increases by about $15 \%$ compared to plain water and also reveals that the flow in the flume tends to decrease this viscosity increment due to shearing effect on the polymers.

The experiments presented below took place in the laboratory of SNF at Andrezieux in France. A specific flume was designed and installed to investigate the effect of drag reduction additives on openchannel flows in different conditions. The $435 \mathrm{~m}$ long flume is smooth, made of fiberglass and epoxy resin with a typical roughness size of $1.6 \mu \mathrm{m}$, of $b=12 \mathrm{~cm}$ wide rectangular cross-section with a constant streamwise slope $S_{0}=0.011 \%$ (see Fig. 2). Note that only the $100 \mathrm{~m}$ downstream-most reach is used for measurements. Underground natural water is pumped before the experiments and stored in a large tank. The inlet then permits to release this water directly towards the flume or to mix it with a controlled concentration of polymers aqueous solution before reaching the flume. The inlet discharge $Q$ is controlled and measured in the upstream feeding system using valves and an electromagnetic flow meter. At the downstream outlet, the flume ends with a free-fall, imposing a critical flow condition before the water is evacuated outside the laboratory.

Figure 2

129 Water depths $h$ are measured using an ultrasonic radar sensor probe (Vegapuls 64 from VEGA) from above the flume. The displacement of the ultrasonic probe along the streamwise axis $x$ of the flume then permits to measure backwater curves. The 3 components of the flow velocity are measured at high sampling frequency locally using an acoustic Doppler velocimeter (16MHz ADV from Sontek). 
133 To improve the signal backscattering, tracers are added to the water and it was verified that these

134 tracers do not affect the impact of the polymers on the drag reduction. The vertical displacement of the

135 velocimeter finally permits to measure vertical profiles of velocity.

\section{Smooth bed experiments}

137

\section{Backwater curves and friction coefficients}

This section aims at characterizing the drag reduction due to additives diluted in the water in an openchannel flow with smooth walls. To do so, five different upstream discharges (see Table 1) are set, under steady state conditions without or with different controlled concentrations of polymers. Keeping a critical downstream depth, a total of 21 subcritical backwater curves are finally measured. Figure 3 exhibits the measured backwater curves over the downstream 100-meters channel reach for a selected discharge without and with four polymer concentrations. Similar figures for other discharges (not shown here) exhibit similar behaviors. Fig. 3 confirms that i) the use of polymers decreases the water depths and, in return increases the flow velocity over the whole measured reach, ii) the water depth reduction increases with the increasing polymer concentration and iii) that the drag reduction does not increase anymore as the polymer concentration exceeds 20 to $30 \mathrm{ppm}$, in agreement with the concept of maximum drag reduction asymptote (MDRA, see White et al., 2018).

Fitting the backwater curve measured with plain water based on the Colebrook-White equation permits to estimate the equivalent bed roughness of the flume to $k_{s} \sim 10^{-4} \mathrm{~m}$. Nonetheless, when using a water/polymer mixture, the Colebrook-White equation does not apply anymore. Consequently, the measured curves are rather fitted using a constant averaged Darcy-Weisbach friction loss coefficient $\lambda$ using:

$$
\frac{d h}{d x}=-\frac{8 g(b h)^{3} S_{0}-Q^{2} \lambda(b+2 h)}{8 b\left(b^{2} h^{3} g-Q^{2}\right)}
$$


with $g$ the acceleration of gravity. Fig.3 confirms that such simplification still fits the measured backwater curves with high fidelity both with plain water (leading to $\lambda \sim 0.017$, in agreement with Moody diagram) and with water/polymer mixtures (leading to lower Darcy-Weisbach coefficients).

Figure 3

The best-fit Darcy-Weisbach coefficients for the 5 tested discharges with plain water and a polymer concentration of $20 \mathrm{ppm}$ are summarized in Table 1. For a given discharge, the difference in water depth with / without polymers leads to a very limited difference in Reynolds number but to a strong decrease of friction coefficient: $\lambda$ is reduced by a factor of about 2 for all discharges. Similarly, the water depth is reduced (and correspondingly the average velocity is increased) by a factor of about 1.1 to 1.2 , i.e. $10 \%$ to $20 \%$. When plotting these results on the well-known Moody diagram (giving $\lambda$ as a function of the Reynolds number and relative roughness for water), the resulting Darcy-Weisbach friction factor $\lambda$ appears to be much lower than what can be obtained by the hydraulically-smooth curve (not shown here). To conclude, the drag reduction in open-channel flows by adding polymers exceeds that of using a perfectly smooth wall, in agreement with pipe flow measurements, reported among others by Tanner (1988).

\section{Table 1}

\section{Velocity profiles}

The present section aims at comparing the vertical profiles of velocity and Reynolds shear stress measured in the smooth open-channel flow with and without the additives. Velocity profiles are measured over the lower $70 \%$ of the flow section using the ADV at a fixed streamwise location $(x=6.87 \mathrm{~m})$ for two discharges $\left(Q=50\right.$ and $\left.100 \mathrm{~m}^{3} / \mathrm{h}\right)$ without polymers and with a concentration equal to $20 \mathrm{ppm}$. Fig. 4 compares the velocity profiles made non-dimensional using the water depth $h$ and average velocity $U_{b}$.

It appears that the four velocity profiles are quite similar to each other and exhibit the expected global shape: a log region near the bed and a quite constant velocity profile further up in the water column in 
the bulk. In Fig. 4, $b / h$ ranges from 0.7 to 1.3 (with $b$ the channel width and $h$ the local water depth) and these profiles are indeed highly similar to typical velocity profiles of narrow and deep openchannel flows in the literature, as shown, for instance by Rendu et al. (2017) with $b / h \sim 1.1$ or Bonakdari et al. (2008) with $b / h \sim 1.8$. Unfortunately, the ADV is not able to measure the details of the velocity profiles in the near-bed region to highlight the transitions between viscous, elastic (with additives) and logarithmic sub-layers. such measurements would require techniques such as PIV (as for Cai et al., 2009) which could not be implemented in the present flume as the lateral walls are not transparent.

Fig. 4 also plots vertical profiles of Reynolds shear stress for the same conditions. The four profiles are in qualitative agreement with a limited shear stress in the upper part of the water column $(z / h>0.2)$ and a rapid increase when approaching the bed, with a maximum shear stress measured at $z / h \sim 0.1$. These profiles are also in qualitative agreement with measurements without polymers by Kironoto and Graf (1995) and the recent calculations without and with polymers performed by White et al. (2018), see their figure 6.

\section{Figure 4}

\section{$\underline{\text { Rough bed experiments }}$}

The previous section showed that the additives permit to reduce the resisting wall friction in smooth bed conditions. The aim of this section is then to verify whether this drag reduction is still observed with a rough bed. The downstream-most, 24 meters long, reach of the flume is modified by including rough walls made of aluminium tear plates of typical tear roughness height equal to $1 \mathrm{~mm}$ (see Fig. 2).

The resulting channel width then reduces to $b_{2}=11 \mathrm{~cm}$.

Similar backwater curves as for the smooth case are measured and plotted in Fig.5 with a critical depth downstream, for two discharges without additives and with $20 \mathrm{ppm}$ of polymers. As for the smooth bed configuration, the water depths appear to strongly decrease when the polymer is included. When using plain water, the best-fit equivalent roughness height increases to $k_{s} \sim 4 \mathrm{~mm}$, which corresponds to an average Darcy-Weisbach coefficient equal to $\lambda \sim 0.05$ for both discharges (Fig. 5). This result is in 
agreement with that of the Moody diagram: for $Q=100 \mathrm{~m}^{3} / \mathrm{h}$ and $h \sim 0.35 \mathrm{~m}$ (see Fig. 5), $k_{s} / D_{h}=0.021$ with $D_{h}$ the hydraulic diameter and $\operatorname{Re}=1.4 \times 10^{5}$, the Moody diagram also predicts $\lambda=0.05$. When adding 20ppm of polymers, the Darcy-Weisbach coefficient reduces to $\lambda \sim 0.037$ for $Q=100 \mathrm{~m}^{3} / \mathrm{h}$ and $\lambda \sim 0.03$ for $Q=50 \mathrm{~m}^{3} / \mathrm{h}$. We thus face a decrease of Darcy-Weisbach coefficient by a factor 1.35 to 1.66 compared to the configuration with plain water, i.e. a smaller decrease than when using a smooth bed but still a notable drag reduction.

Figure 5

Vertical profiles of streamwise velocity are measured in the rough bed configuration in a similar way as for the smooth bed configuration at the same location $(x=6.87 \mathrm{~m})$ for both tested discharges without and with additives and are shown in Fig.6 in the same way as for Fig.4. As for the smooth bed condition, very similar streamwise velocity profiles are measured without and with additives over the rough bed for both discharges with a quite constant streamwise velocity $U_{x} / U_{b} \sim 1.2$ for $z / h>0.4$ and a velocity decrease closer to the bed (Kirkgoz, 1989). Regarding the Reynolds shear stress, the maximum shear stresses $\left(-\left\langle u_{\mathrm{x}}{ }^{\prime} u_{\mathrm{z}}{ }^{\prime}>_{\max } / \mathrm{U}_{\mathrm{b}}{ }^{2} \sim 15 \times 10^{-4}\right)\right.$ observed at $z / h \sim 0.1$ appear to exceed that measured over the smooth bed (Fig.4) but with no notable difference without and with additives.

\section{Figure 6}

As proposed by Virk (1971), it is expected that the roughness effect on the flow depends on the ratio between the equivalent roughness height and the width of the viscous and elastic sublayers away from the wall. This ratio is evaluated by estimating the roughness height parameter $k_{s}{ }^{+}=k_{s} \mathrm{u} * / v$, where the friction velocity $\mathrm{u} *$ is obtained using $u_{*}=U \sqrt{\frac{\lambda}{8}}$, with $U$ the average velocity and $v$ the kinematic viscosity of the water. For a discharge of $Q=50 \mathrm{~m}^{3} / \mathrm{h}$ of the water $+20 \mathrm{ppm}$ mixture: $U \sim 0.4 \mathrm{~m} / \mathrm{s}$, $u_{*} \sim 0.024 \mathrm{~m} / \mathrm{s}$ and $k_{s}{ }^{+} \sim 100$ and for $Q=100 \mathrm{~m}^{3} / \mathrm{h}: U \sim 0.5 \mathrm{~m} / \mathrm{s}, u_{*} \sim 0.034 \mathrm{~m} / \mathrm{s}$ and $k_{s}{ }^{+} \sim 135$. Both backwater curves measured in the rough bed with a concentration of $20 \mathrm{ppm}$ of polymers (Fig.5) are thus in the so-called completely rough regime $\left(k_{s}{ }^{+}>70\right)$, according to Nezu and Nakagawa (1993) among others. According to these authors, in a typical water flow in completely rough regime, "viscous effects disappear because the roughness elements penetrate the fully turbulent logarithmic layer". Besides, for 
a water + polymer mixture, Virk (1971) shows that drag reduction effects decrease as the equivalent roughness height parameter $k_{s}^{+}$increases from 12 up to values larger than the experimental limitations of this author: $k_{s}{ }^{+} \sim 150$. The present observation of drag reduction limitation for the present $k_{s}{ }^{+}=100$ and 135 is thus in fair agreement with this author's observations in rough pipes.

\section{Experiments with emerging obstacles (and smooth wall)}

The previous section showed the ability of additives to reduce the friction coefficient in flows where the resistance is governed by wall friction. The aim of the present section is to evaluate the effect of additives in a flow which resistance is rather governed by drag forces induced by obstacles (Stone and Shen, 2002), with a negligible contribution to the wall friction. To do so, vertical impervious and smooth obstacles of $D=15 \mathrm{~mm}$ wide square section are introduced in the flume, deposited on the bed and emerging through the free-surface (Fig. 7). One obstacle is introduced every meter over the 42 meters downstream most channel reach. The obstacles are not aligned in the streamwise direction, they are rather randomly located from the left to the right bank. Backwater curves for the $Q=100 \mathrm{~m}^{3} / \mathrm{h}$ configuration are shown on Fig.8 with and without additives (and also without obstacles), in the same way as for Fig.2. This figure first confirms that, when using water, adding the obstacles strongly increases the water depth and thus strongly increases the flow resistance, confirming that the flow resistance is dominated by the drag forces on the obstacles. Moreover, Fig. 8 reveals that, in such case, the additives do not permit to reduce the flow resistance and lead to a very similar backwater curve as when using plain water.

\section{Figure 7}

This incapacity of polymers to decrease the drag forces induced by the obstacles is in agreement with the recent findings of Xiong et al. (2017) on the drag reduction effect in flows interacting with an isolated obstacle. To do so, the authors introduce a Reynolds / Weissenberg number phase diagram upon which they indicate the regions for which the drag force induced by the obstacle is reduced, unaffected and enhanced by the inclusion of polymers in the fluid. In the present case, the Reynolds number based on the obstacle diameter equals: 
259

260

261

262

263

and the Weissenberg number (viscous to elastic forces ratio):

$$
\mathrm{Wi}=2 U \tau / D \sim 2 \times 0.6 \times 6.7 \times 10^{-3} / 0.015 \sim 0.5
$$

with $\tau$ the polymer relaxation time estimated as (see Xiong et al., 2017):

$$
\tau \sim \rho \vee R_{o}{ }^{3} /\left(k_{B} T\right) \sim 1000 \times 10^{-6} \times 3 \times 10^{-7} /\left(1.38 \times 10^{-23} \times 293\right) \sim 6.7 \times 10^{-3} \mathrm{~s}
$$

$\rho$ the density of water $\left(1000 \mathrm{~kg} / \mathrm{m}^{3}\right), R_{o} \sim 3 \times 10^{-7} \mathrm{~m}$ the typical size of the polymer statistical sphere, $k_{B}=1.38 \times 10^{-23} \mathrm{~J} / \mathrm{K}$ the Boltzmann constant and $T \sim 293 \mathrm{~K}$ the fluid temperature. According to figure 4 or 6 from Xiong et al. (2017), for $\operatorname{Re}_{\mathrm{D}} \sim 8000$ and Wi $\sim 0.5$ the obstacle drag coefficient is unaffected by the addition of polymers, which explains why the backwater curves in Fig.8 are so similar with and without polymers.

\section{Figure 8}

To conclude, the flow resistance is here governed by drag forces due to obstacles - rather than friction on smooth walls. Considering the associated particulate Reynolds numbers, these drag forces are mainly due to pressure drag and adding polymers has no effect on the head losses and thus on the water depth and average velocity of the flow.

\section{$\underline{\text { Discussions and conclusions }}$}

To the author's knowledge, the present paper is the first work dedicated to the study of the impact of adding to the water a limited concentration of polymers for classical free-surface open-channel flows: 1D subcritical flows over smooth and rough beds, without and with emerging obstacles. These flow configurations are small-scale and simplified versions of typical channel and river flows. These measurements reveal that adding polymers to the water under these conditions:

1) Strongly decreases the drag force that the walls apply on the flow, leading to highly increased mean velocities and highly decreased water depths. The averaged equivalent Darcy-Weisbach 
coefficient is decreased by a factor of about 2 for the smooth bed configuration and about 1.5 for the rough bed configuration. The drag reduction is thus still effective but reduced in magnitude with a roughness parameter $k_{s}+$ larger than 100 , in agreement with previous observations in rough pipes (Virk, 1971)

2) Has no effect on the resistance forces when relatively large obstacles are included in the channel. When the flow resistance is dominated by the drag forces due to these obstacles, the influence of the boundary layers adjacent to the channel walls becomes negligible and no drag reduction is observed anymore, in agreement with Cadot et al. (1998) observations.

3) Hardly modifies the vertical profiles of streamwise velocities and Reynolds shear stress at least away from the wall region.

To summarize, at the laboratory scale, as long as the boundary layer developing along the bottom and side walls of the channel governs the resistance forces, the modification of these boundary layers by the additives permits to highly increase the capacity of a watercourse, i.e. to limit the water depths and specifically the overflows over the side banks. Oppositely if the flow resistance is governed by the drag forces on large scale obstacles, the additives have no effect on the watercourse capacity.

This drag reduction method already proved to be effective for reducing the water depth in sewer networks (Sellin, 1988; Hart et al., 2011) and the present work corroborates these observations as the flow resistance in sewers is mainly dominated by wall frictions and the size of the wall roughness remains usually limited. Oppositely, to the author's knowledge, this method was never tested in geophysical flows such as rivers and the following paragraphs discuss first its expected hydraulic efficiency and second its potential environmental issues. by:

$$
k_{s}+=\frac{k_{s} u^{*}}{v} \approx \frac{k_{s} \sqrt{g R_{h} S_{0}}}{v}
$$


where $k_{s}$ is the equivalent bed roughness and $R_{h}$ the hydraulic radius. Let us consider $k_{s}+=135$ as the threshold for an effective friction reduction by the additives (Fig.5). For typical plain rivers (say $S_{0}=10^{-4}$ ), friction reduction is then expected to be effective (Pich, 2014): for small rivers $\left(R_{h}=1 \mathrm{~m}\right)$ if $k_{s}<4.3 \mathrm{~mm}$, corresponding to small gravel beds, and for big rivers $\left(R_{h}=10 \mathrm{~m}\right)$ with $k_{s}<1.4 \mathrm{~mm}$, corresponding to sand rivers. Still, its real efficiency would depend on river slope, size and bed sediments characteristics, but the $k_{s}+=135$ threshold is also questionable and may depend on the Reynolds number. The impact of obstacles (dikes, bridge piles, boulders, etc...) on the drag reduction should also be considered, though it is expected to be negligible as obstacles are relatively sparse in river reaches.

Regarding the environmental issues, several drawbacks can be listed. A first potential drawback concerns the spatial distribution of the flooding risk: the application of present technique should be considered within a global risk management procedure, considering all the hydrological and human processes - and their associated time scales - at the whole river basin scale. A second potential drawback is related to the environmental impact of polyacrylamide, notably on aquatic organisms, injected in the rivers. Anionic polyacrylamide is widely used in irrigation water (Sojka et al., 2001) or mineral extraction water, where its dissemination was commented by Guezennec et al. (2015). But while the injection in sewers in Canada, reported by Hart et al. (2011), concerns about $30 \mathrm{~kg}$ per hour and this water goes through a water treatment plant before returning to the river, an injection of $10-20$ ppm in a large flooding river of a discharge of about $1500 \mathrm{~m}^{3} / \mathrm{s}$ would lead to an injection of about 50100 Tons of polymer per hour directly in the riverine environment. Present work does not address these effects on the receiving environment, and this technique should be implemented with authorities.

\section{$\underline{\text { References }}$}

Achia B. U., Thompson D. W. 1977. Structure of the turbulent boundary layer in drag reducing pipe flow, Journal of Fluid Mechanics, 81(3), 439-464

Bonakdari H., Larrarte F., Lassabatere L., Joannis C. 2008. Turbulent velocity profile in fullydeveloped open channel flows, Environ Fluid Mech 8, 1-17.

Brostow W. 2008. Drag Reduction in Flow: Review of Applications, Mechanism and Prediction, Journal of Industrial and Engineering Chemistry 14(4), 409-416.

Cadot O, Bonn D, Douady S. 1998. Turbulent drag reduction in a closed flow system: Boundary layer vs bulk effects, Physics of Fluids, 10, 426-436 
Cai W.-H., Li F.-C., Zhang H.-N., Li X.-B., Yu B., Wei J.-J., Kawaguchi Y., Hishida K. 2009. Study on the characteristics of turbulent drag-reducing channel flow by particle image velocimetry combining with proper orthogonal decomposition analysis, Physics of Fluids, 21, 115103.

Guezennec, A. G., Michel, C., Bru, K., Touzé, S., Desroche, N., Mnif, I., \& Motelica-Heino, M. (2015). Transfer and degradation of polyacrylamide-based flocculants in hydrosystems: a review. Environmental Science and Pollution Research, 22(9), 6390-6406.

Han W.J., Dong Y.Z., Choi H.J. 2017. Applications of Water-Soluble Polymers in Turbulent Drag Reduction, Processes, 5, 24.

Harder K. J., Tiederman W. G. 1991. Drag reduction and turbulent structure in two-dimensional channel flows, Philosophical Transactions of the Royal Society of London. Series A: Physical and Engineering Sciences, 336, 1640, 19-34.

Hart J, Cotter L, Jason V. 2011. Polymer Addition to Increase Trunk Sewer Flow Capacity at the Resort Municipality of Whistler during the 2010 Winter Olympic Games, Proceedings of the Water Environment Federation, WEFTEC 2011: session 88, 12, 5763-5774.

Herzhaft B. 2000. Additifs réducteurs de perte de charge en écoulement. Oil \& Gas Science and Technology, Revue de l'IFP, 55 (5), 501-509.

Janosi I. M., Jan D., Szabo K. G., Tel T. 2004. Turbulent drag reduction in dam-break flows, Experiments in Fluids, 37, 219-229.

Kirkgöz M. S. 1989. Turbulent velocity profiles for smooth and rough open channel flow, Journal of Hydraulic Engineering, 115(11), 1543-1561

Kironoto B., Graf W.H. 1995. Turbulence characteristics in rough non-uniform open-channel flow, Proc., Instn Civ. Engrs. Wat. Marit. \& Energy, 112(4), 336-348.

Min T., Yoo J.Y., Choi H., Joseph D.D. 2003. Drag reduction by polymer additives in a turbulent channel flow, Journal of Fluid Mechanics, 486, 213-238.

Nezu, I., Nakagawa H. 1993. Turbulence in open channel flows, IAHR Monograph, Balkema, Rotterdam, The Netherlands.

Pich R . 2014. Method for limiting freshet levels and controlling floods, Patent\# WO 2014199037 A1.

Rendu, Q., Mignot, E., Riviere, N. Lamberti-Raverot B., Puijalon S., Piola F. 2017. Laboratory investigation of Fallopia $\times$ bohemica fruits dispersal by watercourses, Environnement Fluid Mechanics, 17, 1051.

Sojka, R. E., Bjorneberg, D. L., Entry, J. A., Lentz, R. D., \& Orts, W. J. (2007). Polyacrylamide in agriculture and environmental land management. Advances in Agronomy, 92, 75-162.

Schlichting H. 1979. Boundary Layer Theory, McGraw-Hill, New-York, 602-609.

Sellin R.H.J 1988. Application of Polymer drag reduction to sewer flow problems, AIAA paper, 88$366,88366$.

Stone, B. M., \& Shen, H. T. 2002. Hydraulic resistance of flow in channels with cylindrical roughness, Journal of Hydraulic Engineering, 128(5), 500-506

Tanner R. I. 1988. Engineering rheology, Oxford Oxfordshire : Clarendon Press, Oxford Engineering Science Series.

Tiederman W., Luchik T., Bogard, D. 1985. Wall-layer structure and drag reduction, Journal of Fluid Mechanics, 156, 419-437.

Toms B. A. 1949. Some observation on the flow of linear polymer solutions through straight tubes at large Reynolds number, Proceedings of the First International Congress of Rheology vol. II, The Netherlands, Amsterdam, 135-141.

Virk P.S. 1971. Drag reduction in rough pipes. Journal of Fluid Mechanics, 45 (2), 225-246.

Virk P.S. 1975. Drag reduction fundamentals. AIChE Journal, 21, 625-656.

White C. M., Dubief Y., Klewicki J. 2018. Properties of the mean momentum balance in polymer drag-reduced channel flow, Journal of Fluid Mechanics, 834, 409-433. 
383 Xiong Y.L., Bruneau C.H., Yang D. 2017. Numerical study on viscoelastic fluid flow past a rigid body, Applied Mathematical Modelling, 42, 188-208. 

with 20 ppm polymers

\begin{tabular}{|c|c|c|c|c|c|c|c|c|}
\hline \multirow[b]{2}{*}{$\begin{array}{c}\text { Discharge } \\
Q\left(\mathrm{~m}^{3} / \mathrm{h}\right)\end{array}$} & \multicolumn{4}{|c|}{ Plain water } & \multicolumn{4}{|c|}{ Water + 20 ppm polymers } \\
\hline & $\begin{array}{c}\text { Darcy- } \\
\text { Weisbach } \\
\text { coeff. }(\lambda)\end{array}$ & $\begin{array}{c}\text { Water } \\
\text { depth }(\mathrm{m}) \\
@ x \sim 50 \mathrm{~m}\end{array}$ & $\begin{array}{c}\text { Typical } \\
\text { Reynolds } \\
\text { number }\end{array}$ & $\begin{array}{l}\text { Froude } \\
\text { number } \\
@ \mathrm{x} \sim 50 \mathrm{~m}\end{array}$ & $\begin{array}{c}\text { Darcy- } \\
\text { Weisbach } \\
\text { coeff. }(\lambda)\end{array}$ & $\begin{array}{c}\text { Water } \\
\text { depth }(\mathrm{m}) \\
@ x \sim 50 \mathrm{~m}\end{array}$ & $\begin{array}{c}\text { Typical } \\
\text { Reynolds } \\
\text { number }\end{array}$ & $\begin{array}{c}\text { Froude } \\
\text { number } \\
@ \mathrm{x} \sim 50 \mathrm{~m}\end{array}$ \\
\hline 50 & 0.02 & 0.22 & $6 \times 10^{+4}$ & 0.36 & 0.011 & 0.20 & $6 \times 10^{+4}$ & 0.41 \\
\hline 75 & 0.02 & 0.30 & $7 \times 10^{+4}$ & 0.34 & 0.01 & 0.26 & $8 \times 10^{+4}$ & 0.42 \\
\hline 100 & 0.02 & 0.35 & $8 \times 10^{+4}$ & 0.36 & 0.01 & 0.32 & $9 \times 10^{+4}$ & 0.41 \\
\hline 125 & 0.018 & 0.40 & $9 \times 10^{+4}$ & 0.37 & 0.008 & 0.35 & $10 \times 10^{+4}$ & 0.45 \\
\hline 150 & 0.017 & 0.50 & $9 \times 10^{+4}$ & 0.31 & 0.008 & 0.40 & $11 \times 10^{+4}$ & 0.44 \\
\hline
\end{tabular}

388 
391 Figure 1. Rheology of water mixture with and without polymers (20ppm) at $24^{\circ} \mathrm{C}$.

392 Figure 2. Photographs of the flume in the smooth (left) and rough (right) configurations.

393 Figure 3. Backwater curves measured (symbols) and fitted with a constant Darcy-Weisbach coefficient 394 (lines) for a discharge $Q=150 \mathrm{~m}^{3} / \mathrm{h}$ with different concentrations of additives in the smooth bed 395 configuration, with $\mathrm{x}$ the streamwise axis oriented towards upstream and $x=0$ the abscise of the 396 downstream free-fall (the water flows from left to right).

397 Figure 4. Vertical profiles of timely-averaged streamwise velocity (left) and Reynolds shear stress 398 (right) for two discharges, with $20 \mathrm{ppm}$ and without polymers measured in the smooth bed 399 configuration at $x=6.87 \mathrm{~m}$.

400 Figure 5. Backwater curves measured for two discharges without additives and with 20 ppm polymers 401 for the rough bed configuration.

402 Figure 6. Vertical profiles of timely-averaged streamwise velocity (left) and Reynolds shear stress 403 (right) for two discharges, with $20 \mathrm{ppm}$ and without polymers measured in the rough bed configuration 404 at $x=6.87 \mathrm{~m}$.

405 Figure 7. Photograph (top view) of the flow downstream one of the emerging obstacles

406 Figure 8. Backwater curves measured for a discharge $Q=100 \mathrm{~m}^{3} / \mathrm{h}$ with $20 \mathrm{ppm}$ and without additives 407 in the smooth bed with obstacle configuration. 